\title{
Expression of selected molecular factors in two types of endometrial cancer
}

\author{
Anna Markowska ${ }^{1, A, C, D}$, Anna Grybos' ${ }^{2, B, E}$, Andrzej Marszałek ${ }^{3, C}$, Wiesława Bednarek ${ }^{4, B}$, Violetta Filas ${ }^{3, B, C}$, Marian Grybośs, ${ }^{5}$, \\ Janina Markowska ${ }^{6, E, F}$, Radosław Mądry ${ }^{6, B}$, Barbara Więckowska ${ }^{7, C}$, Danuta Nowalińska ${ }^{3, C}$, Monika Szarszewska ${ }^{6, C, E}$ \\ ${ }^{1}$ Department of Perinatology and Gyneacology, Poznan University of Medical Sciences, Poland \\ ${ }^{2}$ Department of Gyneacology and Obstetrics, Faculty of Health Science, Wroclaw Medical University, Poland \\ ${ }^{3}$ Department of Tumour Pathology and Prophylaxis, Poznan University of Medical Sciences, Greater Poland Cancer Centre, Poland \\ ${ }^{4}$ Chair and Clinic of Gynecological Oncology, Medical University of Lublin, Poland \\ ${ }^{5}$ Department of Obstetrics, Faculty of Health Sciences, University of Opole, Poland \\ ${ }^{6}$ Department of Gynecological Oncology, Poznan University of Medical Sciences, Poland \\ ${ }^{7}$ Department of Computer Science and Statistics, Poznan University of Medical Sciences, Poland \\ A - research concept and design; $\mathrm{B}$ - collection and/or assembly of data; $\mathrm{C}$ - data analysis and interpretation; \\ $D$ - writing the article; $E$ - critical revision of the article; $F$ - final approval of the article
}

Address for correspondence

Anna Gryboś

E-mail: annagrybos@yahoo.pl

Funding sources

None declared

Conflict of interest

None declared

Received on June 29,2020

Reviewed on February 4, 2021

Accepted on May 15, 2021

Published online on September 9, 2021

Cite as

Markowska A, Gryboś A, Marszałek A, et al. Expression of selected molecular factors in two types of endometrial cancer. Adv Clin Exp Med. 2021;30(10):1057-1064. doi:10.17219/acem/137383

DOI

10.17219/acem/137383

Copyright

Copyright by Author(s)

This is an article distributed under the terms of the

Creative Commons Attribution 3.0 Unported (CC BY 3.0)

(https://creativecommons.org/licenses/by/3.0/)

\section{Abstract}

Background. Endometrial cancers $(E C)$ are a heterogeneous group of malignant neoplasms differing in etiology, clinical-pathological features and prognosis.

Objectives. To determine the differences between the expression of selected molecular factors and find connections between them in order to isolate possible biomarkers influencing treatment options.

Materials and methods. The investigated data involved archival histological preparations obtained from uterine EC samples taken from 137 patients, treated surgically between 2007 and 2014. The immunohistochemical Dako EnVision ${ }^{\mathrm{TM}}$ Flex+ method was applied.

Results. The expression of ERB, MLH1 and BRCA1 was lower in ECI than in ECII patients. The ERa expression was higher in early Fédération internationale de gynécologie et d'obstétrique ( $F \mid G O)(I A)$ stages than in advanced (IB-IV) stages, while ERß expression was significantly higher in advanced stages compared to stage IA and increased with grading. The BRCA1 expression also increased with grading. In both type I and type || EC patients, ERa expression correlated with MYH9 and BRCA1, while ERß expression correlated with BAP expression. High expression of BRCA1 correlated with several proteins: BAP, MYH9 and FAK. High BAP expression also correlated with high MYH9 expression. A correlation in the expression of these proteins was also demonstrated in the group consisting only of patients with ECI. A significant correlation was found between BAP expression and MYH9 among patients diagnosed with ECI. In the ECII group, no correlation was found between the tested proteins.

Conclusions. The ECl and ECII patients differed in the studied molecular factors, mainly in terms of ER and BRCA1 expression. Changes in BRCA1 expression were linked to alterations in BAP expression, but were also associated with the proteins MYH9 and FAK.

Key words: MYH9, endometrial cancer, BAP, FAK 


\section{Background}

According to global epidemiological statistics, endometrial cancer (EC) is the $6^{\text {th }}$ most common cancer in women. There were over 380,000 new cases of EC in 2018, representing $4.4 \%$ of all female malignancies diagnosed that year. The age-standardized rate of EC per 100,000 women is the highest in Belarus, followed by the Samoan Islands (24.9 and 24.8, respectively). Poland ranks $12^{\text {th }}$ in the incidence of EC. ${ }^{1}$ In the last 10 years, the incidence of EC has increased significantly in many geographical regions of the world, including Europe., ${ }^{2,3}$

Bokhman's hypothesis has led to the identification of 2 basic types of EC: ECI and ECII. The ECI, which is characterized as endometrioid, is associated with a good prognosis and constitutes the large majority of patients, while ECII, which is non-endometrioid, occurs less frequently than ECI and has a more clinically aggressive course and poor prognosis. ${ }^{2,4}$

The molecular characteristics of ECI include mutations in the PTEN suppressor gene and $\beta$-catenin encoding CTNNB1 gene, as well as changes in PIK3CA signaling and in $M M R$ genes (mismatch repair). ${ }^{2,5-7}$ The ECII is characterized by mutations in the TP53, HER-2 neu and BRCA genes. ${ }^{8,9}$

According to Setiawan et al., the risk factor profiles for both EC types are quite similar, suggesting that they share some common etiologic pathways. ${ }^{5}$ Long et al. studied 1170 cases of EC (including types I and II) and found that the germline $M M R$ mutations typical of Lynch syndrome were present in $1.4 \%$ of ECI and $1.6 \%$ of ECII patients. ${ }^{10}$ Molecular changes in ECI and ECII were the reason for genomic analysis (TCGA), in which at least 4 EC subtypes were isolated. ${ }^{11}$

Epidemiological and genetic studies also indicate a relationship between the development of endometrial serous cancer, ECII and BRCA $1 / 2$ mutations. ${ }^{12,13}$ A relationship was also found between the BRCA1 suppressor and $B A P 1$ (BRCA-associated protein-1), which has suppressor effects. This link may affect the etiology of the pathogenesis of BRCA-dependent cancers. ${ }^{14,15}$ The full spectrum of $B A P 1$-dependent tumors is constantly updated, as new associations with other genes are discovered. ${ }^{16-18}$

Cytoplasmic tyrosine kinase, a product of the FAK (focal adhesion kinase) gene located at chromosome 8q24, participates in processes facilitating the progression of malignant tumors, including EC. ${ }^{19}$ Deregulation of the biological function of $F A K$ is involved in cell migration, angiogenesis, cell growth, expression of anti-apoptotic proteins and, more prominently, in the invasion and metastasis of cancer. ${ }^{20,21}$ Upregulation of $F A K$ is observed in both endometrial hyperplasia and carcinoma. ${ }^{21,22}$ Tsai et al. suggested that the participation of $F A K$ in the migration of EC cells is induced by estrogens. ${ }^{23}$

Further research is underway regarding ECI and ECII susceptibility to gene mutations and the isolation of biomarkers for early EC detection. So far, no relationship has been described between MYH9 mutations and EC. However, the results of studies on the expression of MYH9 protein in ovarian and lung cancer indeed have shown clinical and prognostic value. ${ }^{24-26}$ Studies indicate that the $M Y H 9$ gene located at chromosome $22 \mathrm{q} 12$ may act as a suppressor gene in cancer. This gene codes for MYH9 (non-muscle myosin IIA), an actin-binding protein that is responsible for the normal structure of the cytoplasm and is involved in cell division, adhesion and motility, which is critical for cancer invasiveness and metastasis. ${ }^{27,28}$ Further research is ongoing to better understand the prognosis and progression of these cancers and their relation to proteomic biomarkers and microRNAs. ${ }^{29,30}$

\section{Objectives}

This study aimed to determine differences between the expression of selected molecular factors in EC and to find potential relationships between them in order to isolate possible biomarkers influencing treatment options.

\section{Materials and methods}

\section{Samples}

This article is based on a retrospective multicenter study of EC patients. The data consist of archival histological preparations from 137 patients with endometrial carcinomas surgically treated between 2007 and 2014.

Of the 137 EC patients, 33 (24.1\%) were diagnosed with stage IA, 36 (26.3\%) with stage IB, 34 (24.8\%) with stage II, $21(15.3 \%)$ with stage III, and $13(9.5 \%)$ with stage IV. Staging was performed according to Fédération internationale de gynécologie et d'obstétrique (FIGO) staging system (2009).

In the examined group, ECI was found in 106 patients (77.4\%), while ECII was found in 31 (22.6\%) patients. Among the patients diagnosed with type II EC, there were 18 patients with the serous type (13.4\%), 11 patients with clear cell type $(8.3 \%)$ and 2 patients with mucous tissue type (1.4\%) (Table 1$)$.

Well-differentiated endometrial cancer (histological grading G1) was diagnosed in 32 patients (23.4\%), intermediate G2 type in 53 patients (38.7\%) and poorly differentiated G3 type in 52 patients (37.9\%) (Table 1).

The average age of all patients enrolled in the study was 65.8 years. The average age was 65.3 years ( $44-83$ years) in patients with ECI and 67.5 years (34-83 years) in women with ECII (group difference in mean age p >0.05; Table 1).

\section{Immunohistochemistry}

Tissue material was fixed in $10 \%$ buffered formalin at $\mathrm{pH} 7.4$ and placed in a processor. The tissue was embedded in paraffin at $60^{\circ} \mathrm{C}$ using standard histopathological 
Table 1. Clinicopathologic characteristics of studied patients with endometrial cancer

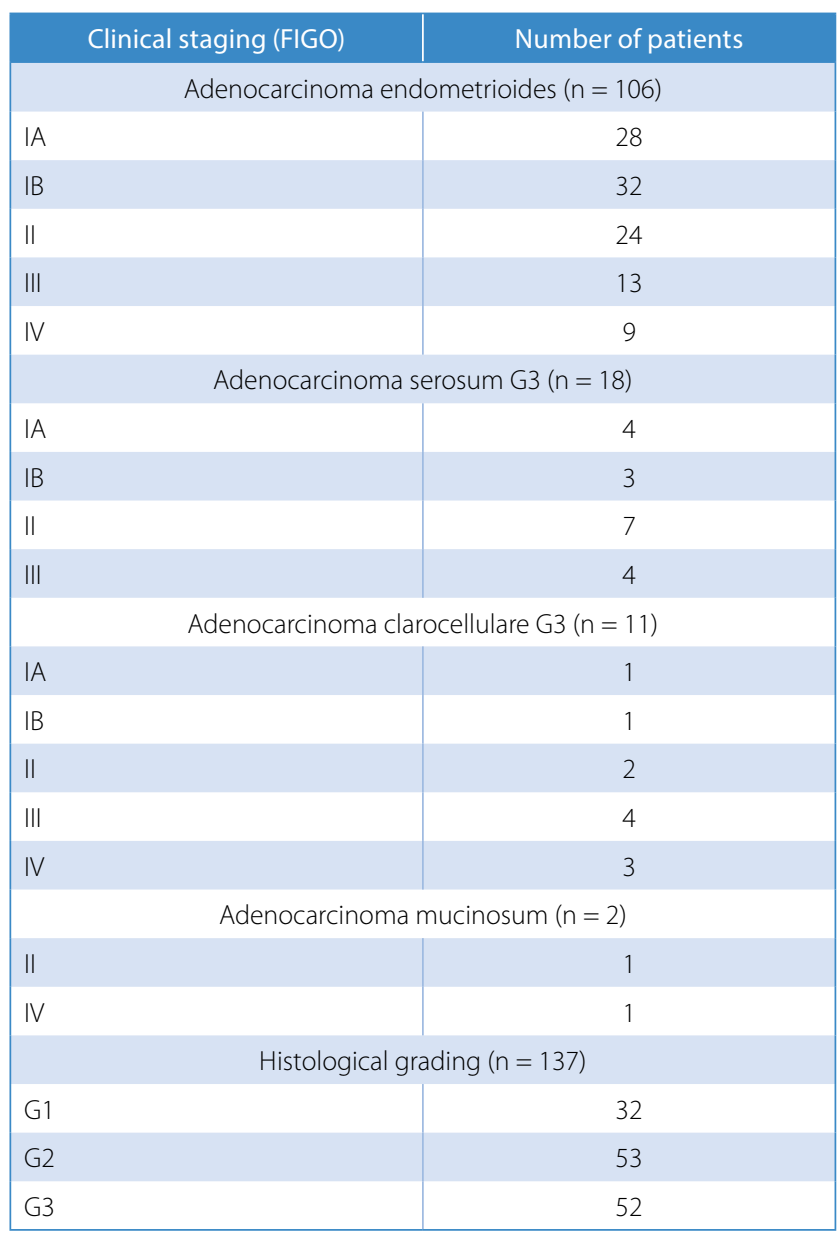

FIGO - Fédération internationale de gynécologie et d'obstétrique (FIGO) staging system.

methods. The marked paraffin blocks were sliced using a microtome into $4-5-\mu \mathrm{m}$ thick sections. The sections were then fixed to microscope slides and left for $1 \mathrm{~h}$ at $60^{\circ} \mathrm{C}$. The Dako EnVision ${ }^{\mathrm{TM}}$ FLEX + system (Dako, Santa Clara, USA) and the immunohistochemical method were used. High pH Target Retrieval Solution (Dako) was used as the buffer in the PT-link apparatus (Dako) at a temperature of $97^{\circ} \mathrm{C}$ for $20 \mathrm{~min}$.

\section{Antibodies}

To test for the presence of antigens in the tissue, the following antibodies were used: ER $\alpha$ (D-12, clone sc-8005; Santa Cruz Biotechnology, Santa Cruz, USA), ER $\beta 1$ (clone MSK042-05; Zytomed Systems, Berlin, Germany), BRCA1 (clone MS110; Abcam, Cambridge, UK), MLH1 (clone ES05; Leica Biosystems, Buffalo Grove, USA), and BAP1 (clone C-4; Abcam). Immunoperoxidase staining was performed on a Dako Autostainer Link 48 apparatus (Dako).

Polyclonal antibodies (Thermo Fisher Scientific, Waltham, USA) were used to determine MYH9 and FAK tumor markers. Sections were incubated with 1 antibody for $20 \mathrm{~min}$. In the case of the FAK antibody, the Dako rabbit linker was used for 15 min. Dako EnVision ${ }^{\text {TM }}$ FLEX/HRP was used with an incubation time of $20 \mathrm{~min}$, and the sections were then incubated with EnVision ${ }^{\mathrm{TM}}$ FLEX DAB + Chromogen for $5 \mathrm{~min}$. Immunoperoxidase staining was performed manually at room temperature. To assess the intensity of ER, MLH1, BRCA1, BAP, MYH9, and FAK protein staining, a four-point scale was used as follows:

0 no reaction;

+ reaction of 1-50 immunopositive cells (nucleus or cytoplasm);

++ reaction of 50-75 immunopositive cells; and

+++ reaction of 75-100 immunopositive cells.

Staining was assessed in 10 fields of view. Preparations exhibiting ++ or +++ staining were considered to represent a positive reaction.

\section{Statistical analyses}

Data are presented as numbers and their corresponding percentages $\mathrm{n}(\%)$. The statistical analyses were based on Pearson's $\chi^{2}$ test or Fisher's exact test. Where sub-tables $2 \times 2$ or larger contingency were analyzed, the $\mathrm{p}$-values were adjusted using Benjamini-Hochberg correction. The frequency of high protein expression in the analyzed groups is presented as the odds ratio (OR) and 95\% confidence interval (95\% CI). All tests were considered significant at $\mathrm{p}<0.05$. The statistical analysis was performed using PQStat v. 1.8.2 software (PQStat Software, Poznań, Poland).

\section{Results}

ER $\alpha, E R \beta, M L H 1, B R C A 1$, and BAF protein manifested nuclear reactions, whereas MYH9 and FAK presented cytoplasmic immunohistochemical reactions (Fig. 1-3).

In EC cells, high protein expression of ER $\alpha$ was found in $37.2 \%$ of patients, ER $\beta$ in $25.6 \%$ of patients, MLH1 in $30.7 \%$ of patients, BRCA1 in $54.8 \%$ of patients, BAP in $63.5 \%$ of patients, MYH9 in $59.1 \%$ of patients, and FAK in only $3.7 \%$ of all patients.

The EC patients were divided into 2 groups based on the histopathological type: ECI $(n=106)$ and ECII ( $\mathrm{n}=31$ ), which included patients with serous, clear cell and mucous carcinomas.

ER $\beta$ and MLH1 expression was lower in the subgroup of patients with ECI ( $22 \%$ compared to $44.3 \%$, p $=0.021$; $\mathrm{OR}=2.71,95 \%$ CI $[1.14,6.43] ; 52.1 \%$ compared to $77.2 \%$, $\mathrm{p}=0.013 ; \mathrm{OR}=3.16,95 \%$ CI $[1.25,8.01]$, respectively). In the case of BRCA1, positive expression of this protein was higher among ECII patients (ECI 24.5\% compared to ECII $51.6 \%, \mathrm{p}=0.004$; OR $=3.28,95 \% \mathrm{CI}[1.43,7.54])$. No statistically significant differences were found in $\mathrm{ER} \alpha$, BAP, MYH9, or FAK expression between the subgroups (all p > 0.05, Table 2). 

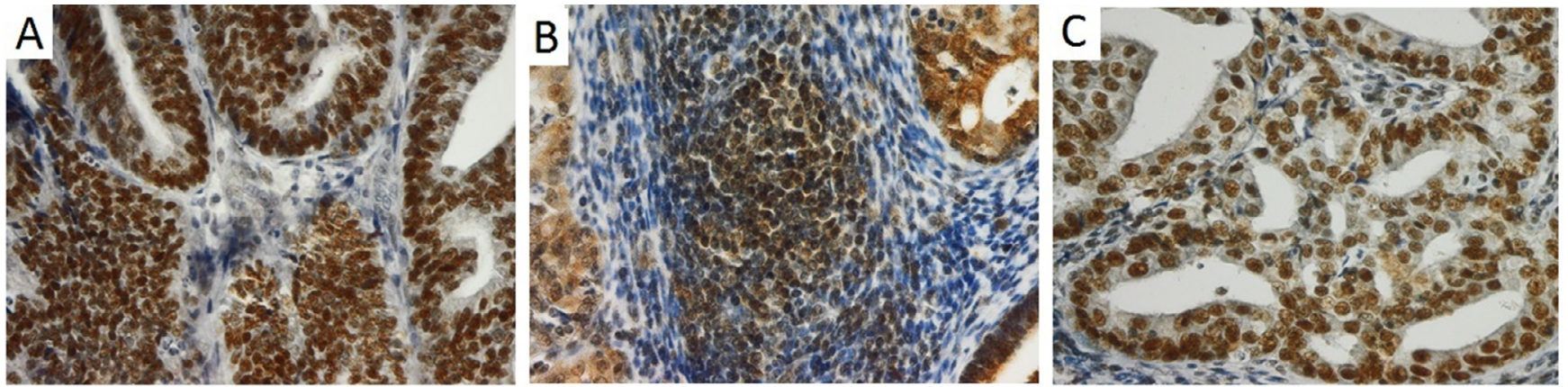

Fig. 1. High expression of ERa 1 (A), ERß (B) and MLH1 (C) in endometrial adenocarcinoma (magnification $\times 10$ )
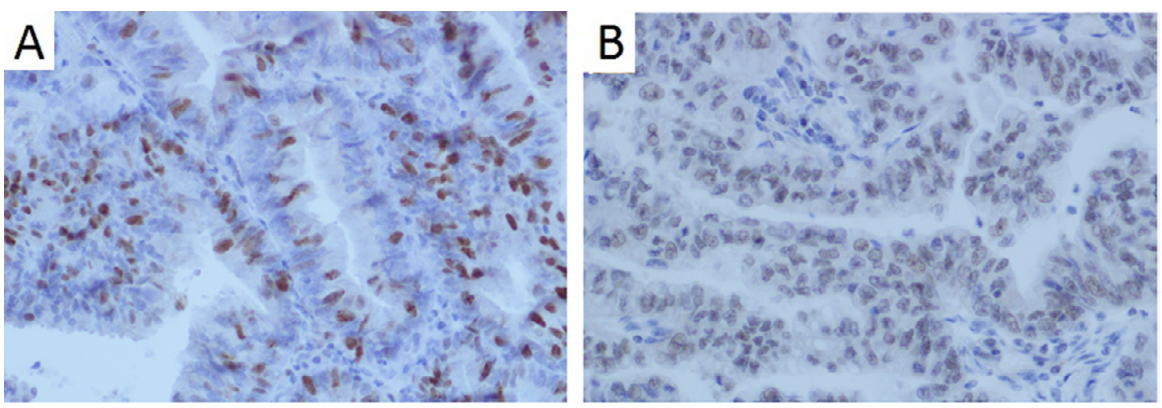

Fig. 2. High expression of BRCA1 (A) and $\mathrm{BAF}(\mathrm{B})$ in endometrial adenocarcinoma (magnification $\times 20$ )
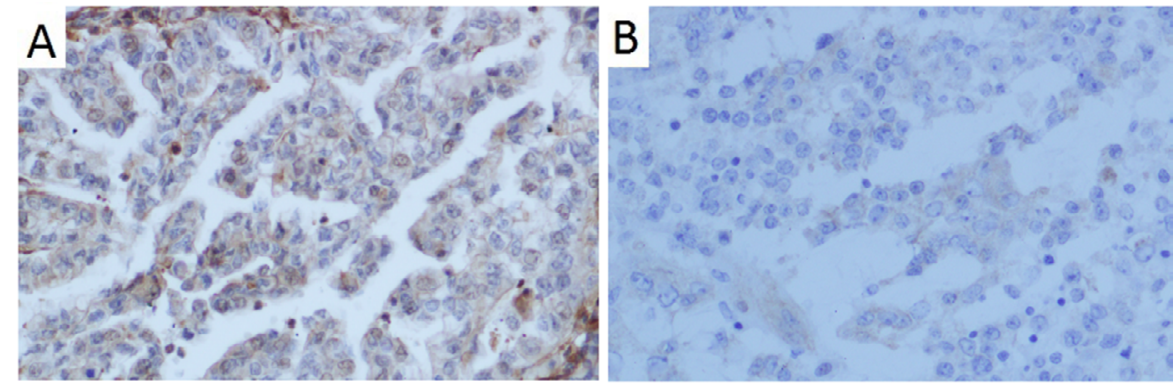

Fig. 3. Positive expression of $\mathrm{MYH} 9(\mathrm{~A})$ and FAK (B) in endometrial adenocarcinoma (magnification $\times 20$ )

Table 2. Percentage of endometrial cancer cases showing high expression of tested protein in ECI and ECII cells

\begin{tabular}{|c|c|c|c|c|c|}
\hline Protein & $\mathrm{ECl}$ & ECII & ${ }^{*} \mathrm{p}$-value & OR & $95 \% \mathrm{Cl}$ \\
\hline Era, n (\%) & $41(40.6)$ & $10(32.3)$ & 0.404 & 0.69 & {$[0.67,1.63]$} \\
\hline $\operatorname{Er} \beta, n(\%)$ & $22(22)$ & $13(43.3)$ & 0.021 & 2.71 & {$[1.14,6.43]$} \\
\hline MLH1, n (\%) & $51(52.1)$ & $24(77.2)$ & 0.013 & 3.16 & {$[1.25,8.01]$} \\
\hline BRCA1, n (\%) & $26(24.5)$ & $16(51.6)$ & 0.004 & 3.28 & {$[1.43,7.54]$} \\
\hline BAP, n (\%) & $66(62.3)$ & $21(67.7)$ & 0.577 & 1.27 & {$[0.54,2.58]$} \\
\hline MYH9, n (\%) & 65 (61.3) & $16(51.6)$ & 0.333 & 0.67 & {$[0.30,1.51]$} \\
\hline FAK, n (\%) & $3(2.8)$ & $2(6.5)$ & 0.344 & 2.37 & {$[0.38,14.85]$} \\
\hline
\end{tabular}

* $p$-value of $x^{2}$ or Fisher's exact test; OR - odds ratio; $95 \% \mathrm{Cl}$ - 95\% confidence interval. Values in bold are statistically significant.

Patients with EC were divided according to the clinical stage of the disease into early (IA) and later (IB-IV) stages. Statistically significant changes only related to ER protein expression. Significantly higher ER $\alpha$ expression was found in patients at the earliest IA disease stage compared to those at more advanced stages (IA 54.8\% compared to IB-IV 33.7\%, $\mathrm{p}=0.034$; OR $=0.42,95 \% \mathrm{CI}[0.18,0.95])$. An inverse relationship was determined for ER $\beta$ (IA $9.7 \%$ compared to IB-IV 32.3\%, $\mathrm{p}=0.013$; OR $=4.46,95 \% \mathrm{CI}$ [1.26, 15.76]; Table 3).
This relationship was also present in the subgroup of patients with ECI (ER $\alpha$ : IA 57.7\% compared to IB-IV 34.7\%, $\mathrm{p}=0.040$; ER $\beta$ : IA 7.7\% compared to IB-IV 27.0\%, $\mathrm{p}=0.042$ ). However, no such relationship was demonstrated for patients with ECII ( $\mathrm{p}>0.05$; Table 3 ). In the total population of patients with EC, tumors with high histological maturity showed significantly lower ER $\beta$ expression than poorly differentiated tumors (G1 19\% compared to G3 37.3\%, p = 0.023).

Tumors of intermediate G2 histological malignancy were characterized by lower expression of BRCA1 protein 
Table 3. Percentage of endometrial cancer cases showing high expression of the tested protein depending on the stage of cancer (IA compared to IB-IV, according to $\mathrm{FIGO}$ )

\begin{tabular}{|c|c|c|c|c|c|}
\hline Protein & FIGO IA & FIGO IB-IV & ${ }^{*} \mathrm{p}$-value & OR & $95 \% \mathrm{Cl}$ \\
\hline Era, n (\%) & $17(54.8)$ & $34(33.7)$ & 0.034 & 0.42 & {$[0.18,0.95]$} \\
\hline $\operatorname{Er} \beta, n(\%)$ & $3(9.7)$ & $32(32.3)$ & 0.013 & 4.46 & {$[1.26,15.76]$} \\
\hline MLH1, n (\%) & $15(51.7)$ & $60(60.0)$ & 0.911 & 1.05 & {$[0.47,2.32]$} \\
\hline BRCA1, n (\%) & $10(30.3)$ & $32(30.8)$ & 0.959 & 1.02 & {$[0.44,2.39]$} \\
\hline BAP, n (\%) & $21(63.6)$ & $66(63.5)$ & 0.985 & 0.99 & {$[0.44,2.23]$} \\
\hline MYH9, n (\%) & $22(66.7)$ & $59(56.7)$ & 0.312 & 0.66 & {$[0.29,1.49]$} \\
\hline FAK, n (\%) & $2(6.1)$ & $3(2.9)$ & 0.594 & 0.46 & {$[0.07,2.88]$} \\
\hline
\end{tabular}

${ }^{*} \mathrm{p}$-value of $\mathrm{x}^{2}$ or Fisher's exact test. OR - odds ratio; $95 \% \mathrm{CI}$ - 95\% confidence interval; FIGO - Fédération internationale de gynécologie et d'obstétrique (FIGO) staging system. Values in bold are statistically significant.

Table 4. The percentage of endometrial cancer cases showing high expression of a given protein depending on the grading (G1 compared to G2 compared to G3)

\begin{tabular}{|c|c|c|c|c|c|c|c|}
\hline Protein & G1 & G2 & G3 & $p$-value & $\begin{array}{c}{ }^{*} \text { p-value G1 } \\
\text { compared } \\
\text { to G2 }\end{array}$ & $\begin{array}{c}{ }^{*} \text { p-value G1 } \\
\text { compared } \\
\text { to G3 }\end{array}$ & $\begin{array}{c}{ }^{*} \text { p-value G2 } \\
\text { compared } \\
\text { to G3 }\end{array}$ \\
\hline Era, n (\%) & $13(44.8)$ & $19(37.3)$ & $19(36.5)$ & 0.738 & 0.759 & 0.759 & 0.940 \\
\hline $\operatorname{Er} \beta, n(\%)$ & $3(10)$ & $13(26.5)$ & $19(37.3)$ & 0.028 & 0.114 & 0.023 & 0.250 \\
\hline MLH1, n (\%) & $19(65.5)$ & $25(51)$ & $31(60.8)$ & 0.403 & 0.488 & 0.674 & 0.488 \\
\hline BRCA1, n (\%) & $8(25)$ & $11(20.8)$ & $23(44.2)$ & 0.024 & 0.649 & 0.114 & 0.030 \\
\hline BAP, n (\%) & $21(65.6)$ & $33(62.3)$ & $33(63.5)$ & 0.952 & 0.899 & 0.899 & 0.899 \\
\hline MYH9, n (\%) & $23(71.9)$ & $30(56.6)$ & $28(53.8)$ & 0.236 & 0.239 & 0.239 & 0.776 \\
\hline FAK, n (\%) & $0(0)$ & $0(0)$ & $5(9.6)$ & 0.017 & 1.000 & 0.227 & 0.081 \\
\hline
\end{tabular}

* $p$-value of $x^{2}$ or Fisher's exact test adjusted with Benjamini-Hochberg correction. OR - odds ratio. Values in bold are statistically significant.

compared to G3 undifferentiated tumors (G2 20.8\% compared to $\mathrm{G} 344.2 \%$, $\mathrm{p}=0.030$ ). In the examined group of patients, no relationship was found between the degree of ER $\alpha$, MLH1, BAP, MYH9, and FAK expression and tumor histological grade (all p > 0.05; Table 4). Among all examined patients with EC, we observed that high expression of ER $\alpha$ was associated with high expression of MYH9 protein $(\mathrm{OR}=2.1,95 \% \mathrm{CI}[1.0,4.5], \mathrm{p}=0.046)$ and with the presence of BRCA1 protein $(\mathrm{OR}=2.1,95 \% \mathrm{CI}[1.0,4.5]$, $\mathrm{p}=0.047)$. High ER $\beta$ expression was associated with high BAP protein expression $(\mathrm{OR}=3.37,95 \% \mathrm{CI}[1.28,6.8]$, $\mathrm{p}=0.007)$.

High BRCA1 expression was associated with high BAP protein expression $(\mathrm{OR}=4.1,95 \% \mathrm{CI}[1.67,10.2]$, $\mathrm{p}=0.001)$, high MYH9 protein expression $(\mathrm{OR}=3.6,95 \% \mathrm{CI}[1.55,8.3]$, $\mathrm{p}=0.002)$, and high FAK protein expression $(\mathrm{OR}=28.01$, 95\% CI $[1.5,519.2]$, $\mathrm{p}=0.002)$. High BAP expression was associated with high MYH9 protein expression $(\mathrm{OR}=3.5$, 95\% CI 1.7- 7.3, $\mathrm{p}<0.001$ ).

Among patients with ECI, high ER $\beta$ expression was associated with high BAP expression $(\mathrm{OR}=4.4,95 \% \mathrm{CI}$ $[1.2,16.1], \mathrm{p}=0.017)$ and high FAK expression $(\mathrm{OR}=9.1$, 95\% CI [0.9, 414.5], $\mathrm{p}=0.047)$. High BRCA1 expression was associated with high expression of MYH9 (OR = 6.9, 95\% CI 1.9-25, $\mathrm{p}=0.001)$, BAP (OR $=4.5,95 \%$ CI $[1.4$, $4.3], \mathrm{p}=0.007)$ and FAK $(\mathrm{OR}=24,95 \% \mathrm{CI}[1.2,481.1]$, $\mathrm{p}=0.013)$. High BAP expression was associated with high MYH9 expression (OR $=3.6,95 \%$ CI $[1.6,8.3], \mathrm{p}=0.002)$.

There was no association between expression of individual proteins among patients with ECII.

\section{Discussion}

Endometrial cancer is a molecularly heterogeneous malignant neoplasm that can present with diverse morbidity, clinical-pathological features and clinical course. ${ }^{2,11,29,30}$ The majority of patients in this study $(77.4 \%)$ were diagnosed with ECI, while the remainder were diagnosed with ECII (22.6\%).

The determined expression of ER $\alpha$ and ER $\beta$ values showed different relationships with the clinical-pathological features of EC. Their diverse roles in type I EC and type II EC have been indicated in numerous studies. ${ }^{31,32}$ We found no differences in ER $\alpha$ expression between histological type (ECI compared to ECII) or histological grading of the cancer $(G)$. However, the values of ER $\alpha$ expression in our study differed significantly between stages according to the FIGO system. ER $\alpha$ expression was higher in stage IA FIGO compared to IB-IV (54.8\% compared to $33.7 \%$, Table 3 ). In a previous study, Backes et al. showed that advanced stage (according to FIGO) patients were 
characterized by ER $\alpha$ expression that was more frequently negative compared to patients at earlier stages. ${ }^{31}$ In their study, $88.6 \%$ of the patients in group I FIGO expressed ER $\alpha$. Other authors have also described a reduction of ER $\alpha$ expression along with rising disease stage. ${ }^{34}$ According to Sho et al., ER $\alpha$ expression in ECII is associated with advanced cancer and worse prognosis. ${ }^{33}$

In our study, high ER $\alpha$ expression (higher in IA FIGO) was significantly correlated with high expression of $\mathrm{MYH} 9$ protein and the presence of BRCA1 protein. This may suggest that both the protein encoded by the suppressor $M Y H 9$ and the protein encoded by the suppressor BRCA1 perform their functions at early clinical stages. ${ }^{10,16,27}$

Although many studies have reported ER $\beta$ involvement in EC carcinogenesis, the data on the correlation of ER $\beta$ expression with disease stage and histological grading remain divergent. ${ }^{34,35}$ Our results showed significantly higher ER $\beta$ expression in type II EC (Table 2) compared to type I EC, as well as higher expression in advanced FIGO stages (Table 3 ) and in poorly differentiated cancers (G3 compared to G1) (Table 4). Thus, high ER $\beta$ expression may be related to aggressive cancers with worse prognosis. Similarly, in the study by Obata et al., high ER $\beta$ expression was correlated with an aggressive EC course, metastasis and/or recurrence. ${ }^{36}$

In our study, high ER $\beta$ expression was correlated with high BAP expression in the whole group of patients. In type I EC patients, we also showed a significant correlation with high BAP and FAK expression. The explanation for this correlation may be the association of ECII with $B R C A \mathrm{mu}-$ tations and the confirmed effect of $B A P-1$ on $B R C A .{ }^{9,15-17}$ In other studies, $F A K$ activity was also reported to be increased in higher EC stages as well as in undifferentiated cancers, i.e., G3. ${ }^{22,37}$

One of the examined proteins in our study was MLH1, which is a product of a gene associated with Lynch syndrome. Of the 2 most common mutations occurring in Lynch syndrome, we chose $M L H 1$ because, according to Lynch and de la Chapelle, the $M L H 1$ mutation occurred in $47 \%$ of patients with hereditary colorectal cancer compared to $19 \%$ of those with a mutation in MSH2. ${ }^{38} \mathrm{MLH} 1$ expression was significantly lower in type I EC compared to type II EC patients, which may indicate that the $M L H 1$ mutation is more common in ECI. We found no difference in expression depending on the clinical stage of FIGO or grading. We also found no correlation between MLH1 expression and other proteins.

The relationship between $B R C A 1$ mutations and ECII has been previously reported. ${ }^{9,12}$ In our study, BRCA1 expression was significantly higher in ECII compared to ECI patients. This suggests that either our patients with ECII did not have the BRCA1 mutation or that we detected inactive proteins; the latter possibility would require further testing. We also found that BRCA1 expression was significantly increased in cancers at G3 compared to cancers at G2, which could be an effect of including all ECII patients in the G3 group, which is the typical histological grade for this type of cancer. ${ }^{79}$ A significant correlation between the expression of BRCA1 and the expression of other proteins was strongly evident. BAP and MYH9 correlations were described in all of the study groups.

In the group of patients with type I EC in our study, there was not only a significant correlation between high expression of BRCA1, MYH9 and BAP, but also with the expression of FAK. As shown in a review by Silver and Livingston, BRCA1 interacts with many proteins by modifying their function. ${ }^{39}$ The correlation of BRCA1 expression with FAK expression may be of clinical significance. This is due to the fact that FAK expression is also associated with a more aggressive EC type, including undifferentiated $\mathrm{G} 3$ cancer. $^{22,37}$

The BAP1 protein is a product of the suppressor BAP1 gene. It regulates key cell pathways like the cell cycle, transcription and signaling DNA damage and also participates in inhibiting the growth of $B R C A$-dependent cancer cells. ${ }^{14,40}$ We did not find differences in BAP1 expression between ECI and ECII groups or between different stages or grading of cancer.

Regarding the other molecular factors, we noted a significant correlation with BAP1 (ER $\beta$ and BRCA1). We found that high BAP expression significantly correlated with high MYH9 expression in the entire group of patients as well as in the subgroup of patients with ECI. According to Fukuda et al., there is a functional correlation between BAP and BRCA1 proteins. ${ }^{15}$ In our study, we showed a correlation between high expression of $\mathrm{ER} \alpha, \mathrm{MYH} 9$ and BRCA1. It can therefore be speculated that BAP interacts with many proteins using, among other features, its deubiquitinating ability. ${ }^{40}$

To the best of our knowledge, this paper is the first to study MYH9 expression in EC. The estimated expression of MYH9 did not differ depending on EC type (I or II), stage or histological grading $(G)$; for all the parameters mentioned, staining was intensive and exceeded 50\% (Tables 2-4). However, we showed that high expression of ER $\alpha, B R C A 1$ and BAP correlates significantly with high MYH9 expression. Therefore, our research indicates a possible functional relationship between $M Y H 9$ and the $B R C A 1$ and $B A P$ suppressor genes, and an indirect relationship with estrogen receptors. These possibilities require further studies.

According to numerous studies, increased FAK expression plays a negative role in EC; it is correlated to FIGO disease stage and shows an increase with decreasing histological maturity of cancer (e.g., a significant increase in G3). ${ }^{22,37}$

\section{Limitations}

In our study, FAK expression was low; this concerns both the FIGO stage and grading in the entire study group (ECI and ECII). In a study by Gabryel et al., FAK expression was evident in $89 \%$ of 134 EC cases. ${ }^{37}$ By contrast, in our 
study, FAK expression was positive in $3.7 \%$ of all patients, with highest perceptible expression in patients with G3 grading (9.6\%). However, the correlation results showed that FAK expression is associated with BRCA1 expression, both in the entire study group and in individual EC types. In addition, in patients with type I EC, high ER $\beta$ expression correlated significantly with FAK expression. Tsai et al. noted a relationship between FAK activity and ER activity in established EC cell lines, but they demonstrated an effect of ER $\alpha$ that we did not find in our study. ${ }^{23}$ Thus, the results of our research regarding the expression of FAK require more extensive study, as they dispute the results of other authors..$^{22,23,37}$

\section{Conclusions}

Among patients with EC, increased expression of ER $\beta$ protein was found in patients with ECII, as well as in patients with higher clinical stages and low histological maturity. The latter finding may be associated with a worse prognosis. Higher ER $\alpha$ protein expression was also evident in patients with FIGO IA, while higher MLH1 protein expression was observed in ECI. The expression of BRCA1 protein was higher in patients with ECI and correlated with BAP, MYH9 and FAK expression. Our results showed high FAK protein expression in only $3.7 \%$ of EC cases - mainly in patients with low histopathological differentiation (G3). The clinical significance of these relationships and potential applications for treatment require further study.

\section{ORCID iDs}

Anna Markowska (1) https://orcid.org/0000-0002-4078-6568 Anna Gryboś (1) https://orcid.org/0000-0002-7456-4373 Andrzej Marszałek (1) https://orcid.org/0000-0002-6055-9151 Wiesława Bednarek (1) https://orcid.org/0000-0001-8151-2697 Violetta Filas (10) https://orcid.org/0000-0003-2028-877X Marian Gryboś (ㅇ https://orcid.org/0000-0003-0216-8088 Janina Markowska (1) https://orcid.org/0000-0002-2893-8389 Radosław Mądry (1) https://orcid.org/0000-0003-0738-2788 Barbara Więckowska (1) https://orcid.org/0000-0002-1811-2583 Danuta Nowalińska (1) https://orcid.org/0000-0000-0000-0001 Monika Szarszewska (1) https://orcid.org/0000-0002-7101-1909

\section{References}

1. Bray F, Ferlay J, Soerjomataram I, Siegel RL, Torre LA, Jemal A. Global cancer statistics 2018: GLOBOCAN estimates of incidence and mortality worldwide for 36 cancers in 185 countries. CA Cancer J Clin 2018;68(6):394-424. doi:10.3322/caac.21492

2. Colombo N, Creutzberg C, Amant F, et al; ESMO-ESGO-ESTRO Endometrial Consensus Conference Working Group. ESMO-ESGO-ESTRO Consensus Conference on Endometrial Cancer: Diagnosis, treatment and follow-up. Ann Oncol. 2016;27(1):16-41. doi:10.1093/annonc/ mdv484

3. Lortet-Tieulent J, Ferlay J, Bray F, Jemal A. International patterns and trends in endometrial cancer incidence, 1978-2013. J Nat/ Cancer Inst. 2018;110(4):354-361. doi:10.1093/jnci/djx214

4. Bokhman JV. Two pathogenetic types of endometrial carcinoma. Gynecol Oncol. 1983;15(1):10-17. doi:10.1016/0090-8258(83)90111-7

5. Setiawan VW, Yang HP, Pike MC, et al. Type I and II endometrial cancers: Have they different risk factors? J Clin Oncol. 2013;31(20):2607-2618. doi:10.1200/JCO.2012.48.2596
6. Huang M, Djordjevic B, Yates MS, et al. Molecular pathogenesis of endometrial cancers in patients with Lynch syndrome. Cancer. 2013; 119(16):3027-3033. doi:10.1002/cncr.28152

7. Sagae S, Susumu N, Viswanathan AN, et al. Gynecologic Cancer Inter Group (GCIG) consensus review for uterine serous carcinoma. Int J Gynecol Cancer. 2014;24(9 Suppl 3):S83-S89. doi:10.1097/IGC. 0000000000000264

8. Felix AS, Yang HP, Bell DW, Sherman ME. Epidemiology of endometrial carcinoma: Etiologic importance of hormonal and metabolic influences. Adv Exp Med Biol. 2017;943:3-46. doi:10.1007/978-3-31943139-0_1

9. Bruchim I, Amichay K, Kidron D, et al. BRCA1/2 germline mutations in Jewish patients with uterine serous carcinoma. Int $J$ Gynecol Cancer. 2010;20(7):1148-1153. doi:10.1111/IGC.0b013e3181ef622d

10. Long B, Lilyquist J, Weaver A, et al. Cancer susceptibility gene mutations in type I and II endometrial cancer. Gynecol Oncol. 2019;152(1): 20-25. doi:10.1016/j.ygyno.2018.10.019

11. Kandoth C, Schultz N, Cherniack AD, et al; Cancer Genome Atlas Research Network. Integrated genomic characterization of endometrial carcinoma. Nature. 2013;497(7447):67-73. doi:10.1038/nature12113

12. Kadan $Y$, Raviv $O$, Segev $Y$, et al. Impact of BRCA mutations on outcomes among patients with serous endometrial cancer. Int $J$ Gynaecol Obstet. 2018;142(1):91-96. doi:10.1002/ijgo.12486

13. Lavie O, Ben-Arie A, Segev Y, et al. BRCA germline mutations in women with uterine serous carcinoma: Still a debate. Int J Gynecol Cancer. 2010;20(9):1531-1534. doi:10.1111/IGC.0b013e3181cd242f

14. Jensen DE, Rauscher FJ III. BAP1, a candidate tumor suppressor protein that interacts with BRCA1. Ann N Y Acad Sci. 1999;886:191-194. doi:10.1111/j.1749-6632.1999.tb09414.x

15. Fukuda T, Tsuruga T, Kuroda T, Nishikawa $H$, Ohta T. Functional link between BRCA1 and BAP1 through histone $\mathrm{H} 2 \mathrm{~A}$, heterochromatin and DNA damage response. Curr Cancer Drug Targets. 2016;16:101-109. doi:10.2174/1568009615666151030102427

16. Jensen DE, Proctor M, Marquis ST, et al. BAP1: A novel ubiquitin hydrolase which binds to the BRCA1 RING finger and enhances BRCA1mediated cell growth suppression. Oncogene. 1998;16:1070-1112. doi:10.1038/sj.onc.1201861

17. Murali R, WiesnerT, Scolyer RA. Tumours associated with BAP1 mutations. Pathology. 2013;45(2):116-126. doi:10.1097/PAT.0b013e32835d0efb

18. Kolluri KK, Alifrangis C, Kumar N, et al. Loss of functional BAP1 augments sensitivity to TRAIL in cancer cells. eLife. 2018;7:e30224. doi:10. 7554/eLife.30224

19. Schaller MD. Biochemical signals and biological responses elicited by the focal adhesion kinase. Biochim Biophys Acta. 2001;1540(1):1-21. doi:10.1016/s0167-4889(01)00123-9

20. Lv PC, Jiang AQ, Zhang WM, Zhu HL. FAK inhibitors in cancer: A patent review. Expert Opin Ther Pat. 2018;28(2):139-145. doi:10.1080/ 13543776.2018.1414183

21. Alowayed N, Salker MS, Zeng N, Sing Y, Lang F. LEFTY2 controls migration of human endometrial cancer cells via focal adhesion kinase activity (FAK) and miRNA-200a. Cell Physiol Biochem. 2016;39(3):815-826. doi:10.1159/000447792

22. Chatzizacharias NA, Giaginis C, Gatzidou E, et al. Expression and clinical significance of FAK and Src proteins in human endometrial adenocarcinoma. Pathol Oncol Res. 2011;17(2):277-285. doi:10.1007/ s12253-010-9310-6

23. Tsai $\mathrm{CL}$, Wu HM, Lin $\mathrm{CY}$, et al. Estradiol and tamoxifen induce cell migration through GPR30 and activation of focal adhesion kinase (FAK) in endometrial cancers with low or without nuclear estrogen receptor a (ERa). PLoS One. 2013;8(9):e72999. doi:10.1371/journal. pone.0072999

24. Liu L, Yi X, Yuan J, et al. MYH9 overexpression correlates with clinicopathoogical parameters and poor prognosis of epithelial ovarian cancer. Oncol Lett. 2019;18(2):1049-1056. doi:10.3892/ol.2019.10406

25. Katono K, Yuichi S, Jiang SX, et al. Prognostic significance of MYH9 expression in resected non-small cell lung cancer. PLoS One. 2015; 10(3):e0121460. doi:10.1371/journal.pone.0121460

26. Pecci A, Ma X, Savoia A, Adelstein RS. MYH9: Structure, functions and role of non-muscle myosin IIA in human disease. Gene. 2018;664: 152-167. doi:10.1016/j.gene.2018.04.048

27. Wang $Y$, Liu S, Zhang Y, Yang Y. Myosin heavy chain 9: Oncogene or tumor suppressor gene? Med Sci Monit. 2019;25:888-892. doi:10. 12659/MSM.912320 
28. Njoku K, Chiasserini D, Whetton AD, Crosbie EJ. Proteomic biomarkers for the detection of endometrial cancer. Cancers (Basel). 2019; 11(10):1572. doi:10.3390/cancers11101572

29. Cerretelii G, Ager A, Arends MJ, Frayling IM. Molecular pathology of Lynch syndrome.J Pathol.2020;250(5):518-531. doi:10.1002/path.5422

30. Zhang L, Kwan SY, Wong KK, Soliman PT, Lu KH, Mok SC. Pathogenesis and clinical management of uterine serous carcinoma. Cancers (Basel). 2020;12(3):E686. doi:10.3390/cancers12030686

31. Backes FJ, Walker CJ, Goodfellow PJ, et al. Estrogen receptor-alpha as a predictive biomarker in endometrioid endometrial cancer. Gynecol Oncol. 2016;141(2):312-317. doi:10.1016/j.ygyno.2016.03.006

32. Kreizman-Shefer H, Pricop J, Goldman S, Elmalah I, Shalev E. Distribution of estrogen and progesterone receptors isoforms in endometrial cancer. Diagn Pathol. 2014;9:77. doi:10.1186/1746-1596-9-77

33. Sho T, Hachisuga T, Nguyen TT, et al. Expression of estrogen receptor-a as a prognostic factor in patients with uterine serous carcinoma. Int J Gynecol Cancer. 2014;24(1):102-106. doi:10.1097/IGC.00000000 00000029

34. Hapangama DK, Kamal AM, Bulmer JN. Estrogen receptor $\beta$ : The guardian of the endometrium. Hum Reprod Update. 2015;21(2): 174-193. doi:10.1093/humupd/dmu053
35. ChakravartyD, Srinivasan R, Ghosh S, Gopalan S, Rajwanshi A, Majumdar S. Estrogen receptor beta1 and the beta2/betacx isoforms in non-neoplastic endometrium and in endometrioid carcinoma. Int J Gynecol Cancer. 2007;17(4):905-913. doi:10.1111/j.1525-1438.2006.00851.x

36. Obata T, Nakamura M, Mizumoto $Y$, et al. Dual expression of immunoreactive estrogen receptor $\beta$ and $p 53$ is a potential predictor of regional lymph node metastasis and postoperative recurrence in endometrial endometrioid carcinoma. PLoS One. 2017;12(11): e0188641. doi:10.1371/journal.pone.0188641

37. Gabriel B, Hasenburg A, Waizenegger M, Orlowska-Volk M, Stickeler E, zur Hausen A. Expression of focal adhesion kinase in patients with endometrial cancer: A clinicopathologic study. Int J Gynecol Cancer. 2009;19(7):1221-1225. doi:10.1111/IGC.0b013e3181b33c61

38. Lynch HT, de la Chapelle A. Hereditary colorectal cancer. NEngl JMed. 2013;348(10):919-932. doi:10.1056/NEJMra012242

39. Silver DP, Livingston DM. Mechanisms of BRCA1 tumor suppression. Cancer Discov. 2012;2(8):679-684. doi:10.1158/2159-8290.CD-12-0221

40. Wang A, Papneja A, Hyrcza M, Habeeb A, Ghazarian D. Gene of the month: BAP1. J Clin Pathol. 2016;69(9):750-753. doi:10.1136/jclinpath-2016-203866 